\title{
The Effects of Secondary Iron Overload and Iron Chelation on A Radiation-Induced Acute Myeloid Leukemia Mouse Model
}

Lap Shu Alan Chan ( $\nabla$ eertri.chan@mail.utoronto.ca )

University of Toronto https://orcid.org/0000-0003-1409-8638

\section{Lilly ChunHong Gu}

Sunnybrook Research Institute

Richard A. Wells

Sunnybrook Health Sciences Centre

\section{Research article}

Keywords: Secondary iron overload, iron chelation, radiation induced acute myeloid leukemia, leukemogenesis, myelodysplastic syndrome.

Posted Date: October 5th, 2020

DOI: https://doi.org/10.21203/rs.3.rs-72210/v1

License: (c) (i) This work is licensed under a Creative Commons Attribution 4.0 International License. Read Full License 


\section{Abstract}

Background: Patients with myelodysplastic syndrome (MDS) require chronic red blood cell (RBC) transfusion due to anemia. Multiple RBC transfusions cause secondary iron overload and subsequent excessive generation of reactive oxygen species (ROS), which leads to mutations, cell death, organ failure, and inferior disease outcomes. We hypothesize that iron loading promotes AML development by increasing oxidative stress and disrupting important signaling pathways in the bone marrow cells (BMCs). Conversely, iron chelation therapy (ICT) using deferasirox may reduce AML risk by lowering iron burden in the iron-loaded animals.

Methods: We utilized a radiation-induced acute myeloid leukemia (RI-AML) animal model. Iron overload was introduced via intraperitoneal injection of iron dextran, and iron chelation via oral gavage of deferasirox. A total of 86 irradiated B6D2F1 mice with various levels of iron burden were monitored for leukemia development over a period of 70 weeks. The Kaplan-Meier estimator was utilized to assess leukemia free survival. In addition, a second cohort of 30 mice was assigned for early analysis at 5 and 7 months post-irradiation. The BMCs of the early cohort were assessed for alterations of signaling pathways, DNA damage response and gene expression. Statistical significance was established using Student's t-test or ANOVA.

Results: Iron loading in irradiated B6D2F1 mice accelerated AML development. However, there was a progressive decrease in AML risk for irradiated mice with increase in iron burden from 7.5 to 15 to $30 \mathrm{mg}$. In addition, ICT decreased AML incidence in the $7.5 \mathrm{mg}$ iron-loaded irradiated mice, while AML onset was earlier for the $30 \mathrm{mg}$ iron-loaded irradiated mice that received ICT. Furthermore, analysis of BMCs from irradiated mice at earlier intervals revealed accelerated dysregulation of signaling pathways upon iron loading, while ICT partially mitigated the effects.

Conclusions: We concluded that iron is a promoter of leukemogenesis in vivo up to a peak iron dose, but further iron loading decreases AML risk by increasing cell death. ICT can partially mitigate the adverse effects of iron overload, and to maximize its benefit this intervention should be undertaken prior to the development of extreme iron overload.

\section{Background}

For myelodysplastic syndrome (MDS) patients who are chronically anemic, sustained red blood cell (RBC) transfusion leads inevitably to secondary hemochromatosis with devastating pathophysiological consequences. To mitigate the risk of iron-related morbidity and premature mortality, iron chelation therapy (ICT) is recommended in transfusion dependent iron-overloaded patients with lower risk MDS, even though the evidence that ICT is effective in influencing these outcomes is weaker than it is for patients with thalassemia major (1).

Retrospective reviews of registry data suggested that iron overload in MDS may promote the development of acute myeloid leukemia (AML) (2). Although an excess incidence of AML is not seen in 
thalassemia major, such an association in MDS may nonetheless be plausible. Hereditary hemochromatosis is associated with several forms of human carcinomas in liver, lung and colon $(3,4)$. establishing the principle that iron can promote cancer development. In addition, it must be borne in mind that MDS - a clonal myeloid disorder that is intrinsically linked to AML development and that is characterized by genomic instability - can be expected to be more susceptible than thalassemia major to an AML-promoting effect.

Proof that iron overload promotes the progression of MDS to AML would have a profound effect on the aims and breadth of ICT in this disease, and could have a positive impact in both low and high risk MDS. We utilized a radiation-induced AML (RI-AML) B6D2F1 mouse model to investigate the hypothesis that extrinsic iron overload can promote AML development.

\section{Methods}

\section{Animals}

B6D2F1 mice were obtained from the Jackson Laboratory (Bar Harbor, ME, USA) and Charles River Canada (St. Constant, QC, Canada), respectively. Upon arrival, all mice were randomized and housed in unisex groups of 5 or less per cage in a temperature and humidity-controlled room maintained on a 12:12 h light/dark cycle in a pathogen-free facility at Sunnybrook Research Institute.

\section{Treatments}

All chemicals were purchased from Sigma-Aldrich (St. Louis, MO, USA) unless stated otherwise. For radiation treatment, nine-week-old male B6D2F1 mice were subjected to non-lethal total-body irradiation at $300 \mathrm{cGy}$ delivered in a Cs-137 small animal irradiator. Three hours after irradiation, the mice were inoculated with $0.5 \mathrm{mg}$ dexamethasone sodium phosphate (Omega Laboratories, Montreal, QC, Canada) by subcutaneous injection. Mice began to receive iron or sham treatment at 2 weeks after irradiation. Iron dextran (1 mg iron equivalent) or the corresponding dosage of dextran (from Leuconostoc spp., $\mathrm{M}_{\mathrm{r}}$ $\sim 6,000$ ) diluted in phosphate-buffered saline (PBS) to a total volume of $200 \mu \mathrm{l}$, was delivered by intraperitoneal injection for 5 days per week until the desired iron burden is reached. Iron chelation therapy was initiated after the end of iron loading. Deferasirox (Novartis, Dorval, QC, Canada) was suspended in $0.5 \%$ hydroxypropylcellulose (a gift from Nippon Soda Co. Ltd, Tokyo, Japan) and administered by oral gavage at 10 or $40 \mathrm{mg} / \mathrm{kg} /$ day for 7 days a week over 4 or 8 weeks.

The main cohort (Figure S1) consisted of 8 treatment groups with varying iron $(\mathrm{mg}) / \mathrm{ICT}(\mathrm{mg} / \mathrm{kg} / \mathrm{day})$ dosage (total number $=86$ ): $0 / 0$ (control, $C 1 . X$ and $C 2 . X, N=13), 7.5 / 0(C 3 . X$ and $C 4 . X, N=13), 15 / 0$ (C5.X and C6.X, $N=10), 30 / 0$ (C7.X and C8.X, $N=10), 7.5 / 10$ (C9.X and C10.X, $N=10), 7.5 / 40$ (C11.X and C12.X, $N=10), 30 / 10$ (C13.X and C14.X, $N=10)$, and 30/40 (C15.X and C16.X, $N=10)$. The individual mouse was considered to be an experimental unit. The sample size calculation was based on $30 \% \mathrm{RI}-$ AML incident rate (5), with $30 \%$ margin of error at $95 \%$ confidence level - a smaller samples size was 
selected in order to screen wider range of iron burden and iron chelation dosage. In addition, a separate cohort of 30 animals were assigned for early analysis at 5 and 7 months post-irradiation (Figure S1).

\section{Monitoring and analysis}

The body weight of all irradiated B6D2F1 mice was measured weekly for the 70 weeks post-irradiation observation period. Overt leukemia was suspected when the subject lost $20 \%$ of its body weight, showed signs of illness, and presented leukemic blasts in its tail vein peripheral blood smear. Diagnosis of AML was made based on the Bethesda proposals for classification of nonlymphoid hematopoietic neoplasms in mice (6). The mice were sacrificed using asphyxiation with carbon dioxide followed by cervical dislocation according to the following criteria: 1 ) became ill ( $20 \%$ weight lost, lack of activity, hunched posture, etc), 2) assigned for early analysis, 3 ) after the 70 weeks observation period. Tissue samples, including peripheral blood (PB), hind limb bones, spleen, liver, and heart, were collected and analyzed. PB count was measured by the Sunnybrook Health Science Centre Hematology Laboratory Service. PB morphology was evaluated by May-Grünwald-Giemsa staining of air-dried smear. At least one of the hind limb bones and other harvested organs were fixed for 24 hours in neutral buffered $10 \%$ formalin solution followed by decalcification for the bones, paraffin embedding, slicing, and staining with hematoxylin and eosin by the Sunnybrook Research Institute Histology Core Facility. Iron accumulation was also confirmed in the organs of the iron-loaded mice using Prussian Blue staining (not shown).

\section{Bone marrow cells (BMCs) processing and analysis}

BMCs for each mouse were obtained from the remaining hind limb bones by flushing the medullary cavity with PBS containing $2 \%$ fetal bovine serum (FBS, Life Technologies, Burlington, ON, Canada). Mature RBC from the BMCs were lysed using ACK lysing buffer (Life Technologies). The BMCs were then washed and resuspended in PBS with $2 \%$ FBS for subsequent flow cytometry and DNA/RNA/protein analysis (See the supplementary methods for further details). An aliquot of BMCs was also prepared for cytospin and stained with May-Grünwald-Giemsa stains for the evaluation of cell morphology.

\section{Figures and data analysis}

All figures and statistical analysis were prepared by GraphPad Prism 5 (GraphPad Software, Inc., La Jolla, CA, USA) or Microsoft Excel 2007. Data are presented as mean \pm SD. Statistical significance was determined by Student's t-test or analysis of variance (ANOVA) and set at $P<0.05$. Post-hoc analysis of significant ANOVA results was performed using the Tukey's method. Homogeneity of variances was assessed by F-test or Bartlett's test. AML free survival between different treatment groups was plotted on Kaplan-Meier (KM) survival curves and analyzed by the Mantel-Cox test or log-rank test for trend. All statistical tests were two sided. Clustergram for $\mathrm{RT}^{2}$ Profiler PCR Arrays are created by the web-based algorithm provided by QIAGEN (http://www.sabiosciences.com/).

\section{Results}

\section{Effects of iron and ICT on radiation-induced AML}


During the 70 weeks observation period, 28 (32.6\%) of the 86 mice were found dead or needed to be sacrificed due to illness (Table 1). Among these mice, 15 were diagnosed with AML, while the other 13 died from other causes ranging from preputial abscess to tumors at various locations (Table 2). Since irradiation in mice is specifically associated with AML (5), we decided to censor other causes of death and focus our analysis on AML. Manifestation of AML in our animal model was marked by severe weight drop of at least $20 \%$ and the presence of blasts in PB (Fig. 1A-C). In mice with leukemia, the size of the myeloid compartment in the $\mathrm{PB}$, based on $\mathrm{CD} 11 \mathrm{~b}^{+}$population, was also expanded in the $\mathrm{PB}$ in comparison to $\mathrm{B} 22 \mathrm{O}^{+} \mathrm{CD} 3 \mathrm{e}^{+}$lymphoid population (Fig. 1D, E). The condition was fatal within 4 weeks after the weight drop. Other manifestations of AML include hepatomegaly or splenomegaly (Table 2), blast infiltration into organs (Figure S2), homogenous BMCs with high proportion of immature cells (Figure S3), expansion of immature ( $\mathrm{Lin}^{-} \mathrm{CD} 45^{+}$or $\mathrm{Lin}^{-} \mathrm{CD} 45^{\mathrm{low} /-}$ ) hematopoietic populations (Figure S4), and the presence of $\mathrm{CD}_{11} \mathrm{~b}^{-} \mathrm{Gr}-1^{+}$population in the BMCs (Figure S5).

Table 1

Characteristics of the B6D2F1 mice in the main cohort (C1.X to C16.X).

\begin{tabular}{|c|c|c|c|c|c|c|c|c|}
\hline Treatment (iron/ICT) & $0 / 0$ & $7.5 / 0$ & $7.5 / 10$ & $7.5 / 40$ & $15 / 0$ & $30 / 0$ & $30 / 10$ & $30 / 40$ \\
\hline & C1.X & C3.X & C9.X & C11.X & C5.X & C7.X & C13.X & C15.X \\
\hline & C2.X & C4.X & C10.X & C12.X & C6.X & C8.X & C14.X & C16.X \\
\hline$N$ & 13 & 13 & 10 & 10 & 10 & 10 & 10 & 10 \\
\hline Total iron burden (mg) & 0 & 7.5 & 7.5 & 7.5 & 15 & 30 & 30 & 30 \\
\hline Deferasirox (mg/kg/d) & 0 & 0 & 10 & 40 & 0 & 0 & 10 & 40 \\
\hline \multirow{2}{*}{$\begin{array}{l}\text { Mean initial body weight } \\
\text { (g) }\end{array}$} & 27.12 & 28.21 & 32.93 & 30.51 & 27.68 & 27.32 & 31.19 & 31.69 \\
\hline & $\frac{ \pm}{1.57}$ & \pm 2.1 & \pm 2.85 & \pm 1.79 & $\frac{ \pm}{3.32}$ & \pm 1.78 & \pm 1.48 & \pm 3.11 \\
\hline \multirow{2}{*}{$\begin{array}{l}\text { Mean maximum body } \\
\text { weight }(\mathrm{g})\end{array}$} & 52.35 & 50.48 & 56.37 & 50.38 & 52.56 & 55.91 & 51.95 & 56.73 \\
\hline & $\stackrel{ \pm}{3.37}$ & $\frac{ \pm}{7.05}$ & \pm 4.64 & \pm 4.13 & $\frac{ \pm}{6.05}$ & \pm & \pm 5.27 & \pm 7.52 \\
\hline Mortality due to AML & $\begin{array}{l}0 \\
(0 \%)\end{array}$ & $\begin{array}{l}5 \\
(38 \%)\end{array}$ & $\begin{array}{l}1 \\
(10 \%)\end{array}$ & $\begin{array}{l}3 \\
(30 \%)\end{array}$ & $\begin{array}{l}2 \\
(20 \%)\end{array}$ & $\begin{array}{l}1 \\
(10 \%)\end{array}$ & $\begin{array}{l}3 \\
(30 \%)\end{array}$ & $\begin{array}{l}0 \\
(0 \%)\end{array}$ \\
\hline Total mortality & $\begin{array}{l}2 \\
(15 \%)\end{array}$ & $\begin{array}{l}7 \\
(54 \%)\end{array}$ & $\begin{array}{l}3 \\
(30 \%)\end{array}$ & $\begin{array}{l}4 \\
(40 \%)\end{array}$ & $\begin{array}{l}3 \\
(30 \%)\end{array}$ & $\begin{array}{l}3 \\
(30 \%)\end{array}$ & $\begin{array}{l}3 \\
(30 \%)\end{array}$ & $\begin{array}{l}4 \\
(40 \%)\end{array}$ \\
\hline
\end{tabular}


Table 2

Cause of death (AML or non-AML) in the main cohort (C1.X to C16.X).

\begin{tabular}{|c|c|c|c|c|c|c|}
\hline Label & Iron/ICTa & $\begin{array}{l}\text { LFS/OS } \\
\text { (weeks) }^{\mathrm{b}}\end{array}$ & $\begin{array}{l}\text { Final body } \\
\text { weight (g) }\end{array}$ & $\begin{array}{l}\text { Final liver } \\
\text { weight (g) }\end{array}$ & $\begin{array}{l}\text { Final spleen } \\
\text { weight (mg) }\end{array}$ & Diagnosis $^{c}$ \\
\hline \multicolumn{7}{|l|}{$A M L$} \\
\hline C3.3 & $7.5 / 0$ & $35.8 / 37.1$ & 33.5 & 2.53 & 260 & $\begin{array}{l}\text { Monocytic } \\
\text { leukemia }\end{array}$ \\
\hline C3.6 & $7.5 / 0$ & $54.0 / 57.0$ & 45.0 & - & - & $\begin{array}{l}\text { Myeloid } \\
\text { leukemia }^{d}\end{array}$ \\
\hline C3.7 & $7.5 / 0$ & $41.0 / 43.0$ & 36.3 & - & - & $\begin{array}{l}\text { Myeloid } \\
\text { leukemia }^{d}\end{array}$ \\
\hline C4.1 & $7.5 / 0$ & $58.7 / 60.0$ & 47.1 & 3.83 & 1085 & $\begin{array}{l}\text { Monocytic } \\
\text { leukemia }\end{array}$ \\
\hline C4.5 & $7.5 / 0$ & $25.4 / 27.7$ & 29.0 & 2.22 & 367 & $\begin{array}{l}\text { Monocytic } \\
\text { leukemia }\end{array}$ \\
\hline C10.1 & $7.5 / 10$ & $31.3 / 35.0$ & 31.6 & 7.29 & 1560 & $\begin{array}{l}\text { Monocytic } \\
\text { leukemia }\end{array}$ \\
\hline C11.4 & $7.5 / 40$ & $37.3 / 38.3$ & 34.1 & 3.64 & 1609 & $\begin{array}{l}\text { Monocytic } \\
\text { leukemia }\end{array}$ \\
\hline C11.5 & $7.5 / 40$ & $63.1 / 69.0$ & 40.7 & 2.06 & 86 & $\begin{array}{l}\text { Myeloid } \\
\text { leukemia }\end{array}$ \\
\hline C12.5 & $7.5 / 40$ & $36.3 / 41.6$ & 36.4 & 2.01 & 930 & $\begin{array}{l}\text { Myelomoncytic } \\
\text { leukemia }\end{array}$ \\
\hline C6.1 & $15 / 0$ & $55.7 / 57.0$ & 42.9 & 3.94 & 789 & $\begin{array}{l}\text { Monocytic } \\
\text { leukemia }\end{array}$ \\
\hline C6.5 & $15 / 0$ & $52.7 / 54.0$ & 52.2 & 4.01 & 579 & $\begin{array}{l}\text { Myeloid } \\
\text { leukemia }^{\mathrm{d}}\end{array}$ \\
\hline C7.4 & $30 / 0$ & $67.1 / 67.1$ & 58.9 & 3.42 & 548 & $\begin{array}{l}\text { Myelomoncytic } \\
\text { leukemia }\end{array}$ \\
\hline C13.3 & $30 / 10$ & $42.1 / 45.0$ & 36.9 & 3.80 & 742 & $\begin{array}{l}\text { Myeloid } \\
\text { leukemia }^{d}\end{array}$ \\
\hline C13.4 & $30 / 10$ & $33.3 / 36.4$ & 33.1 & 6.01 & 1170 & $\begin{array}{l}\text { Monocytic } \\
\text { leukemia }\end{array}$ \\
\hline C14.2 & $30 / 10$ & $55.6 / 55.6$ & 41.3 & 3.32 & 293 & $\begin{array}{l}\text { Myeloid } \\
\text { leukemiad }^{d}\end{array}$ \\
\hline \multicolumn{7}{|c|}{ Non-AML (censored) } \\
\hline C1.4 & $0 / 0$ & 56.6 & 43.9 & 2.04 & 97 & Other \\
\hline
\end{tabular}




\begin{tabular}{|c|c|c|c|c|c|c|}
\hline Label & Iron/ICT ${ }^{a}$ & $\begin{array}{l}\text { LFS/OS } \\
\text { (weeks) }\end{array}$ & $\begin{array}{l}\text { Final body } \\
\text { weight (g) }\end{array}$ & $\begin{array}{l}\text { Final liver } \\
\text { weight (g) }\end{array}$ & $\begin{array}{l}\text { Final spleen } \\
\text { weight (mg) }\end{array}$ & Diagnosis $^{c}$ \\
\hline $\mathrm{C} 2.4$ & $0 / 0$ & 50.0 & 49.9 & 2.12 & 1380 & $\begin{array}{l}\text { Metastasized } \\
\text { tumor }\end{array}$ \\
\hline C4.4 & $7.5 / 0$ & 16.7 & 37.2 & 1.46 & 63 & Other \\
\hline C10.2 & 7.5/10 & 69.3 & 51.8 & 1.78 & 80 & Other \\
\hline C10.5 & 7.5/10 & 68.6 & 45.5 & 6.30 & 175 & Liver tumor \\
\hline C12.1 & $7.5 / 40$ & 69.1 & 35.6 & 1.13 & 140 & Lung tumor \\
\hline C5.1 & $15 / 0$ & 67.1 & 52.0 & 2.88 & 187 & $\begin{array}{l}\text { Abdominal } \\
\text { tumor }\end{array}$ \\
\hline C7.3 & $30 / 0$ & 52.6 & 37.3 & - & - & Other \\
\hline C8.5 & $30 / 0$ & 39.6 & 28.4 & 2.08 & 87 & Other \\
\hline C15.1 & $30 / 40$ & 54.6 & 38.9 & 2.71 & 421 & $\begin{array}{l}\text { Lymphoid } \\
\text { neoplasm }\end{array}$ \\
\hline C15.2 & $30 / 40$ & 31.6 & 29.2 & 1.88 & 89 & Liver tumor \\
\hline C15.4 & $30 / 40$ & 44.0 & 60.8 & 3.87 & 205 & Bone tumor \\
\hline C16.2 & $30 / 40$ & 67.4 & 58.0 & 3.40 & 389 & $\begin{array}{l}\text { Abdominal } \\
\text { tumor }\end{array}$ \\
\hline \multicolumn{7}{|c|}{${ }^{a}$ Iron burden $(\mathrm{mg})$ / ICT by deferasirox $(\mathrm{mg} / \mathrm{kg} / \mathrm{d})$} \\
\hline \multicolumn{7}{|c|}{ b Leukemia (AML) free survival / overall survival (post-irradiation, weeks) } \\
\hline \multicolumn{7}{|c|}{$\begin{array}{l}{ }^{c} \text { Diagnosis of AML was made based on the Bethesda proposals for classification of nonlymphoid } \\
\text { hematopoietic neoplasms in mice }\end{array}$} \\
\hline \multicolumn{7}{|c|}{ d AML subtype not determined } \\
\hline \multicolumn{7}{|c|}{ e Myeloid leukemia with maturation } \\
\hline
\end{tabular}

Based on the Bethesda proposals for classification of nonlymphoid hematopoietic neoplasms (6), 7 mice were diagnosed with monocytic leukemia characterized by the presence of a monocytic component in the BMCs, 2 mice had myelomoncytic leukemia with both neutrophilic and monocytic components, and one mouse had myeloid leukemia with maturation characterized by the presence of a neutrophilic component (Table 2). The other 5 mice were confirmed to have myeloid leukemia, but the exact subtype could not be determined (Table 2). All of the AML cases during the observation period developed in mice that belonged to the iron-loaded or iron-loaded/ICT groups. Of the control mice that were irradiated but not iron-loaded, two eventually developed AML after the end of the observation period (C1.2 and C2.5). Within the observation period, the earliest AML onset was at 25.4 weeks after irradiation and the latest was at 69 
weeks. Leukemia (AML)-free survival (LFS) in iron-loaded and iron-loaded/ICT mice were $74 \%$ and $82 \%$, respectively, and both were not significantly different when compared with the control mice $(P=0.06$ and $P=0.12$, respectively $)$ or with each other $(P=0.49$ Fig. $2 A)$. Among the iron-loaded mice, the highest rate of AML was observed in the group receiving $7.5 \mathrm{mg}$ iron with LFS at $58 \%(P<0.05, H R 9.29$ vs controls, Fig. 2B). Surprisingly, there appeared to be an inverse relationship between iron dose and AML, even though the relationship was not statistically significant. The LFS and earliest AML onset in the $7.5 \mathrm{mg}$, $15 \mathrm{mg}$, and $30 \mathrm{mg}$ iron-loaded groups were $58 \% / 25.4$ weeks, $80 \% / 52.7$ weeks, and $88 \% / 67.1$ weeks, respectively (logrank test for trend $P=0.10$ ). Deferasirox treatment improved LFS in the $7.5 \mathrm{mg}$ ironloaded group ( $80 \%$ vs $58 \%$ without ICT, Fig. 2 C). In addition, a significant trend in LFS was observed when the groups were arranged according to the amount of iron loading, ranking lowest-to-highest from control, $7.5 \mathrm{mg}$ iron/ICT, to $7.5 \mathrm{mg}$ iron (logrank test for trend $\mathrm{P}<0.05$ ). Conversely, ICT had the opposite effect on the $30 \mathrm{mg}$ iron-loaded group, in which a more rapid AML onset was observed after deferasirox treatment (33.3 vs 67.1 weeks without ICT, Fig. 2D).

\section{The role of iron loading in leukemogenesis of RI-AML}

To elucidate the mechanism by which iron contributes to radiation-induced leukemogenesis, we examined the irradiated BMCs (iBMCs) from a separate cohort of mice at earlier intervals of 5 and 7 months after irradiation (Figure S1). We injected the mice with $7.5 \mathrm{mg}$ iron dextran (or $5 \mathrm{mg}$ before the second iron loading), which had the highest incidence rate of AML among the tested iron doses. To assess the effects of ICT, some of the iron-loaded mice had also received oral deferasirox at $40 \mathrm{mg} / \mathrm{kg} /$ day ( $\mathrm{N}=5$ per treatment). The early analysis cohort comprised $0 / 0 \mathrm{iron}(\mathrm{mg}) / \mathrm{ICT}(\mathrm{mg} / \mathrm{kg} / \mathrm{day})$ (T1.X), 5/0 (T2.X), 5/40 (T3.X) for 5 months post-irradiated mice; and 0/0 (T4.X), 7.5/0 (T5.X), 7.5/40 (T6.X) for 7 months post-irradiated mice. None of the mice from the early cohort developed overt AML. For comparison, we used iBMCs from 5 of the mice in the main cohort that developed AML: C2.5 $(0 / 0)$, C6.1 (15/0), C7.4 (30/0), C11.4 (7.5/40), and C13.4 (30/10).

Assessments of the iBMCs from the earlier cohort alongside the AML group suggested a pattern of progressive molecular alterations including alteration of signaling pathways, DNA damage response, and gene expression pattern (see supplementary results for further details). We characterized 3 stages of radiation-induced leukemogenesis in the iBMCs without iron loading from pre-AML stage 1 at 5 months post-irradiation $(0 / 0, T 1 . X)$, to pre-AML stage 2 at 7 months post-irradiation $(0 / 0, T 4 . X)$, to eventual $A M L$ beyond 18 months (Fig. 3). There were progressive alterations including activation of Akt, NF-kB, Wnt, and antioxidant defenses, as well as inactivation of JNK, C/EBPS, and PTEN. Iron loading appeared to induce intermediate stages between stages 1 and 2 as well as between stage 2 and AML, which we defined as stage $1 \mathrm{a}$ and $2 \mathrm{a}$, respectively. At 5 months post-irradiation for stage $1 \mathrm{a}, 5 \mathrm{mg}$ iron loading in iBMCs (iiBMCs $5 / 0, T 2 . X$ ) induced alterations that partly resemble stage 2 , in which further changes to Akt, NF-KB, JNK, and DNA damage response were observed when compared to stage 1 . Conversely, the expression C/EBPS and the expression of antioxidant genes were altered in stage 2, but this was not the case for the 5 months iiBMCs at stage $1 \mathrm{a}$. Therefore, we conclude that stage $1 \mathrm{a}$ is at a more advanced leukemogenic state than stage 1 but has not yet reach stage 2. Moreover, iron loading had additional 
effects in including activation of Foxo3a. The additional effects may be cellular responses to handle the excess iron. Alternatively, non-iron-loaded iBMCs may display a similar expression pattern that resembles stage 1 a when they transform from stage 1 to 2 . In the 7 months iiBMCs for stage $2 a(7.5 / 0, T 5 . X)$, the tumor suppressor PTEN was downregulated, which is a critical step towards AML development. We therefore conclude that stage $2 a$ is a possible intermediate state between stage 2 and AML. Furthermore, the more advanced leukemogenic state and sustained DNA damage may be responsible for the earlier onset and higher incidence of AML for the iron-loaded mice. Our ICT regimen did not completely reverse the effects of iron loading on the iron-chelated iiBMCs (ciiBMCs) at 5 (5/40, T3.X) and 7 (7.5/40, T6.X) months post-irradiation. ICT partially reduced iron-dependent DNA damage response in the 5 months ciiBMCs, and dampened iron-induced transcription dysregulations of many genes in the 5 and 7 months ciiBMCs, and eventually lowered AML incidence. Therefore, we concluded that the leukemogenic states of ciiBMCs were between stage 1 and 1 a at 5 months post-irradiation, and between stage 2 and $2 a$ at 7 months post-irradiation.

\section{Discussion}

In inherited anemia and in genetic hemochromatosis, severe chronic iron overload leads to early mortality mainly by inducing hepatic and cardiac injury (7-9). ICT removes excess iron and improves survival, but incomplete removal of iron may increase the risk of carcinogenesis, including hepatocellular carcinoma and hematopoietic neoplasia for thalassemia patients with secondary iron overload $(10,11)$. Furthermore, the risk of hepatocellular carcinoma is elevated for chronically transfused thalassemia patients with cirrhotic liver or viral hepatitis $(12,13)$, suggesting that secondary iron overload may further promote carcinogenesis in organs that are already in a premalignant state. Anemic MDS patients acquire iron overload as a consequence of chronic transfusion (14). However, unlike thalassemia, the hematopoietic tissues of MDS patients are vulnerable to leukemic transformation. We therefore hypothesized that iron loading may accelerate AML progression in MDS. Our study was designed to investigate the potential of iron loading to induce impairment and eventually $A M L$, specifically when the hematopoietic tissue is in a premalignant state.

\section{B6D2F1 mice are sensitive to RI-AML}

To answer this question, we used a standard radiation/dexamethasone protocol to induce AML in B6D2F1 mice, which have been utilized commonly in studies of iron loading. Although there have been no reports of the rate of RI-AML in B6D2F1 mice, we reasoned that this model should show an intermediate sensitivity to radiation, since it is the $\mathrm{F} 1$ progeny of a radiation sensitive (DBA2) and a radiation insensitive (C57BI/6) strain (15). Indeed, our B6D2F1 cohort developed RI-AML with prolonged latency at beyond 18 months. For comparison, the frequency of RI-AML in the SJL/J strain is $10-30 \%$ at approximately 12 months post-irradiation (5), while further treatment with corticosteroid increases the AML rate to $50-70 \%$ at a mean latent period of 10 months post-irradiation (16). In addition, the frequency of RI-AML in the CBA strain is $25 \%$ at 18-24 months (17). Molecular analysis of the iBMCs from the 5 and 7 months cohort suggested progressive gene expression dysregulations that are consistent with 
leukemogenesis (Fig. 3) - increased cell survival/proliferation (Akt, NF-kB and Wnt) and decreased apoptosis/tumor suppression (JNK, C/EBPS and PTEN). Iron is a potent promoter of RI-AML with reduced latency at 7 months and $40 \%$ incidence rate. Further gene expression dysregulations were also observed in the iiBMCs from the 5 and 7 months cohort.

The use of total BMCs enabled the assessment of gene expression dysregulation at the population level. Nevertheless, the composition of BMCs, especially at non-leukemic state, is heterogeneous with different hematopoietic linages at various stages of differentiation. Hence, the observed transcriptional changes in this study could also be interpreted as the change in sub-population composition at different time interval in relation to iron burden. Future investigation can focus on selected sub-population, such as CD34 + KSL cells (18), to elucidate the leukemogenic effects of iron on early hematopoietic progenitors.

\section{Leukemia-promoting iron dosages are consistent with previous studies of iron and cancer}

In animal models, iron overload induces or promotes various types of tumors (19). However, iron loading is not known to induce leukemia as a sole agent and there are few studies that have evaluated the role of iron overload to promote leukemogenesis. We employed the RI-AML mouse model to assess the effect of iron loading on leukemogenesis. Indeed, iron loading shortened the latency of RI-AML and increased the incidence rate. RI-AML was most prominent in the $7.5 \mathrm{mg}$ iron-loaded group. In other studies, cumulative iron dose by parenteral injection for the induction or promotion of cancer varies from $2.3 \mathrm{mg}$ to $640 \mathrm{mg}$ based on a $35 \mathrm{~g}$ mouse (19). A large portion of these studies were conducted using iron dextran at approximately $21 \mathrm{~g}$ of total iron burden. The total iron dose to promote RI-AML in this study is therefore generally consistent with the literature. Nevertheless, a direct comparison cannot be made between BM and other tissues regarding their carcinogenic sensitivity to iron due to the use of different methods to induce carcinogenesis, and because the basal iron level and the severity of iron accumulation are known to be mouse strain dependent $(20,21)$. The iron status of an individual is also influenced by other factors including age, gender and cell/tissue type (20). These factors may influence the tolerance and physiological response of BMCs to excess iron, thereby modulating the effects of iron loading to induce cell damage and promote leukemogenesis. Therefore, comparisons of iron sensitivity across studies should be conducted with caution.

\section{Dose-response relationship between iron burden and leukemogenesis}

Interestingly, the occurrence of RI-AML and total iron burden was inversely correlated. There was a progressive decrease in $\mathrm{AML}$ frequency and corresponding increase in latency for irradiated mice with iron burden from 7.5 to 15 to $30 \mathrm{mg}$. In addition, ICT by deferasirox on the 7.5 and $30 \mathrm{mg}$ iron-loaded irradiated mice produced opposite effects - we observed lower AML incidence in the $7.5 \mathrm{mg}$ iron-loaded mice that received ICT (compared to $7.5 \mathrm{mg}$ iron-loaded mice that received no ICT), while AML onset was earlier for $30 \mathrm{mg}$ iron-loaded mice that received ICT (compared to $30 \mathrm{mg}$ iron-loaded mice that received no ICT). Bronze discoloration was observed in the ICT-treated $30 \mathrm{mg}$ iron-loaded mice (not shown), 
suggesting that our ICT protocol did not result in the complete removal of excess iron. We conjecture that the risk of AML is influenced by the pro-apoptotic and pro-mutagenic properties of iron at different doses (Fig. 4). In this model, iron-induced oxidative stress damages cellular components, including DNA, lipid, and protein. Incomplete repair of this damage contributes to leukemogenesis. The magnitude of AML risk correlates with iron dose but plateaus after a certain iron burden is reached. On the other hand, iron also has the potential to induce cell death by apoptosis or ferroptosis; induction of cell death by iron has a steeper dose-response curve and surpasses the rate of leukemia induction at high doses. Thus, cells with exceedingly high iron burden undergo apoptosis or ferroptosis instead of transforming into leukemiainitiating cells. Consequently, at higher iron doses the reduction of cell viability lowers the risk of AML. The resulting two-stage effects of iron loading on AML risk resembles a biphasic dose-response curve, which accounts for the initial rise of AML risk due to mutagenesis and subsequent drop due to reduced viability. A two-stage mutation model has also been proposed for radiation carcinogenesis, in which the risk of cancer increases up to a certain radiation dose and then declines at higher dose $(22,23)$. This notion was further demonstrated by Di Majo et al. using male CBA/Cne mice, in which RI-AML peaked at 3 Gy and declined at 5 and $7 \mathrm{~Gy}(24)$.

This study screened a wide range of iron burden by means of iron loading and chelation dosage, which enable the establishment of the relationship between secondary iron overload and RI-AML. However, the statistical power of our findings is limited by the relatively small sample size per treatment group, the modest RI-AML incident rate (15 out of 86 mice, 17.4\%), and the unexpected decrease in RI-AML rate with higher iron burden. Jin et al reported impaired hematopoietic progenitors and shortened overall survival upon iron loading in a MDS mouse model that utilize the RUNX1-S291fs mutation (25). Interestingly, the background strain of their model, C57BL/6, is known to be more resistant to both AML development and iron overload $(15,21)$. In future study, it would be useful to utilize the genetic variations of iron tolerance between different mouse strains to evaluate the relationship between iron, MDS and leukemogenesis.

\section{Conclusions}

The pathogenesis of RI-AML shares several similarities with that of MDS, including the early emergence of leukemia-initiating cells, the long latency before AML transformation, and the disrupted bone marrow microenvironment. Radiation-induced BM injury is a valid approach to mimic the pre-leukemic state in the BM of MDS patients. Our study confirmed the ability of iron to promote RI-AML. This supports the notion that secondary iron overload as a consequence of chronic transfusion may accelerate AML transformation in MDS. Molecular changes similar to those seen in the iron-loaded irradiated BMCs may also occur in the BMCs from MDS patients. ICT dampened some of the iron-induced alteration in the irradiated BMCs and improved RI-AML survival. Conversely, ICT increased AML risk for irradiated mice with high iron burden. Therefore, the total iron burden may have a crucial role in determining the AML risk in RI-AML as well as in MDS. However, the relationship may be complicated due to the biphasic doseresponse nature between iron and AML. Risk estimation will require the assessment of the pro-apoptotic and pro-mutagenic effects of iron on the HSCs from MDS patients with varying iron burden. If the AML risk peaks at an iron dose that is higher than relevant iron burden in the clinical setting, then ICT may be 
beneficial to all iron overloaded MDS patients, especially those who are already at higher risk of AML transformation. On the other hand, if the AML risk peaks at an iron dose that is within the range of clinically relevant iron burden, then adequate ICT will be crucial for patients with severe iron overload. Moreover, early intervention to control iron burden by ICT may be an effective measure to avoid the potential AML risk due to iron overload. Current guidelines regarding the use of ICT in MDS patients with iron overload do not take into account the potential AML risk due to iron overload (1). It is also uncertain if current recommended serum ferritin target (usually at 1,000 $\mu \mathrm{g} / \mathrm{L}$ ) for ICT is sufficiently low to avoid the potential iron-related AML risk. Thus, our findings point to the necessity of further research to verify the role of secondary iron overload to accelerate AML transformation in MDS.

\section{List Of Abbreviations}

BMCs - bone marrow cells

ICT - iron chelation therapy

LFS - leukemia-free survival

MDS - myelodysplastic syndrome

PB - peripheral blood

$\mathrm{RBC}$ - red blood cell

RI-AML - radiation-induced acute myeloid leukemia

ROS - reactive oxygen species

\section{Declarations}

\section{Ethics approval and consent to participate}

All experimental protocols were conducted with the approval of the Animal Care Committee of Sunnybrook Research Institute.

\section{Consent for publication}

Not applicable.

\section{Availability of data and materials}

The datasets used and/or analysed during the current study are available from the corresponding author on reasonable request.

\section{Competing interests}


The authors declare that they have no competing interests.

\section{Funding}

This work was funded by a generous donation from the estate of J. Douglas Crashley. This work was also supported by grants and fellowships from Leukemia \& Lymphoma Society of Canada, Novartis Pharmaceuticals Canada, an Ontario Student Opportunity Trust Funds Award, and a Canadian Blood Services Graduate Fellowship. The design of the study; collection, analysis, and interpretation of data; and in writing the manuscript were solely the responsibility of the authors.

\section{Authors' contributions}

L.C. and R.W. contributed to the initiating idea. L.C. and L.G. contributed to the animal experiments including flow cytometry. L.C. performed the gene expression experiments. L.C. and R.W. analysed all the data and wrote the manuscript. All authors have read and approved the manuscript.

\section{Acknowledgements}

The authors acknowledge Dr. Alden Chesney for his guidance with histological analysis.

\section{References}

1. Gattermann N. Overview of guidelines on iron chelation therapy in patients with myelodysplastic syndromes and transfusional iron overload. International journal of hematology. 2008;88(1):24-9.

2. Leitch HA. Controversies surrounding iron chelation therapy for MDS. Blood reviews. 2011;25(1):1731.

3. Toyokuni S. Role of iron in carcinogenesis: cancer as a ferrotoxic disease. Cancer science. 2009;100(1):9-16.

4. Fargion S, Valenti L, Fracanzani AL. Hemochromatosis gene (HFE) mutations and cancer risk: expanding the clinical manifestations of hereditary iron overload. Hepatology. 2010;51(4):1119-21.

5. Rivina L, Davoren M, Schiestl RH. Radiation-induced myeloid leukemia in murine models. Hum Genomics. 2014;8:13.

6. Kogan SC, Ward JM, Anver MR, Berman JJ, Brayton C, Cardiff RD, et al. Bethesda proposals for classification of nonlymphoid hematopoietic neoplasms in mice. Blood. 2002;100(1):238-45.

7. Bartfay WJ, Bartfay E. Iron-overload cardiomyopathy: evidence for a free radical-mediated mechanism of injury and dysfunction in a murine model. Biol Res Nurs. 2000;2(1):49-59.

8. Bartfay WJ, Dawood F, Wen WH, Lehotay DC, Hou D, Bartfay E, et al. Cardiac function and cytotoxic aldehyde production in a murine model of chronic iron-overload. Cardiovasc Res. 1999;43(4):892900.

9. Prati D. Benefits and complications of regular blood transfusion in patients with beta-thalassaemia major. Vox sanguinis. 2000;79(3):129-37. 
10. Borgna-Pignatti C, Garani MC, Forni GL, Cappellini MD, Cassinerio E, Fidone C, et al. Hepatocellular carcinoma in thalassaemia: an update of the Italian Registry. Br J Haematol. 2014;167(1):121-6.

11. Karimi M, Giti R, Haghpanah S, Azarkeivan A, Hoofar H, Eslami M. Malignancies in patients with betathalassemia major and beta-thalassemia intermedia: a multicenter study in Iran. Pediatr Blood Cancer. 2009;53(6):1064-7.

12. Maakaron JE, Cappellini MD, Graziadei G, Ayache JB, Taher AT. Hepatocellular carcinoma in hepatitis-negative patients with thalassemia intermedia: a closer look at the role of siderosis. Ann Hepatol. 2013;12(1):142-6.

13. Mancuso A. Hepatocellular carcinoma in thalassemia: A critical review. World J Hepatol. 2010;2(5):171-4.

14. Malcovati L. Red blood cell transfusion therapy and iron chelation in patients with myelodysplastic syndromes. Clinical lymphoma \& myeloma. 2009;9 Suppl 3:S305-11.

15. Boulton E, Cole C, Knight A, Cleary H, Snowden R, Plumb M. Low-penetrance genetic susceptibility and resistance loci implicated in the relative risk for radiation-induced acute myeloid leukemia in mice. Blood. 2003;101(6):2349-54.

16. Resnitzky P, Estrov Z, Haran-Ghera N. High incidence of acute myeloid leukemia in SJL/J mice after X-irradiation and corticosteroids. Leuk Res. 1985;9(12):1519-28.

17. Major IR. Induction of myeloid leukaemia by whole-body single exposure of CBA male mice to x-rays. Br J Cancer. 1979;40(6):903-13.

18. Ema H, Morita Y, Nakauchi H, Matsuzaki Y. Isolation of murine hematopoietic stem cells and progenitor cells. Curr Protoc Immunol. 2005;Chapter 22:Unit 22B 1.

19. Beguin Y, Aapro M, Ludwig H, Mizzen L, Osterborg A. Epidemiological and nonclinical studies investigating effects of iron in carcinogenesis-a critical review. Crit Rev Oncol Hematol. 2014;89(1):115.

20. Hahn P, Song Y, Ying GS, He X, Beard J, Dunaief JL. Age-dependent and gender-specific changes in mouse tissue iron by strain. Exp Gerontol. 2009;44(9):594-600.

21. Fleming RE, Holden CC, Tomatsu S, Waheed A, Brunt EM, Britton RS, et al. Mouse strain differences determine severity of iron accumulation in Hfe knockout model of hereditary hemochromatosis. Proc Natl Acad Sci U S A. 2001;98(5):2707-11.

22. Lindsay KA, Wheldon EG, Deehan C, Wheldon TE. Radiation carcinogenesis modelling for risk of treatment-related second tumours following radiotherapy. Br J Radiol. 2001;74(882):529-36.

23. Hall EJ. Radiation, the two-edged sword: cancer risks at high and low doses. Cancer J. 2000;6(6):343-50.

24. Di Majo V, Coppola M, Rebessi S, Saran A, Pazzaglia S, Pariset L, et al. The influence of sex on life shortening and tumor induction in CBA/Cne mice exposed to $X$ rays or fission neutrons. Radiat Res. 1996;146(1):81-7. 
25. Jin $X$, He X, Cao X, Xu P, Xing Y, Sui S, et al. Iron overload impairs normal hematopoietic stem and progenitor cells through reactive oxygen species and shortens survival in myelodysplastic syndrome mice. Haematologica. 2018;103(10):1627-34.

\section{Figures}
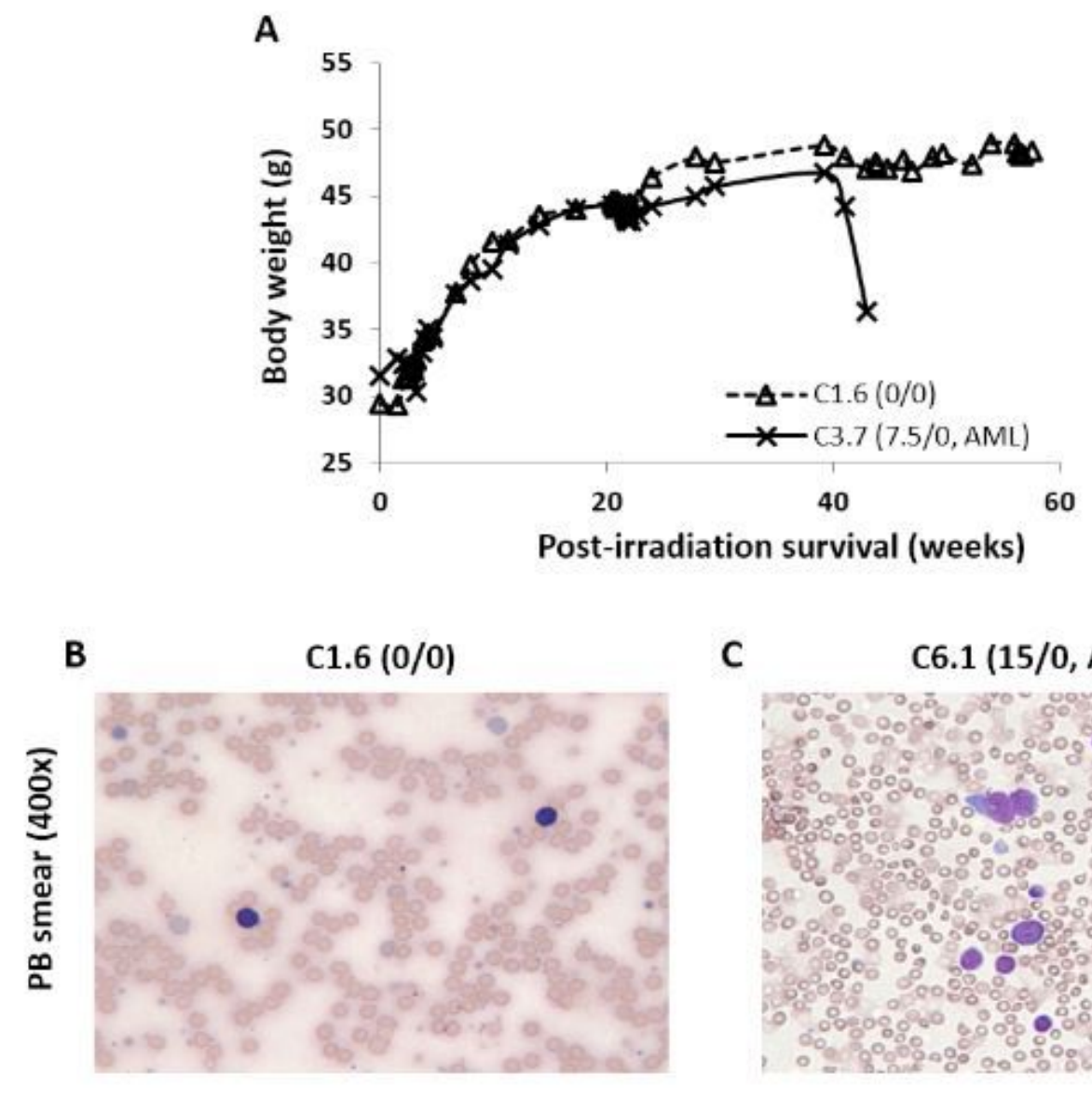

C $\quad$ C6.1 (15/0, AML)
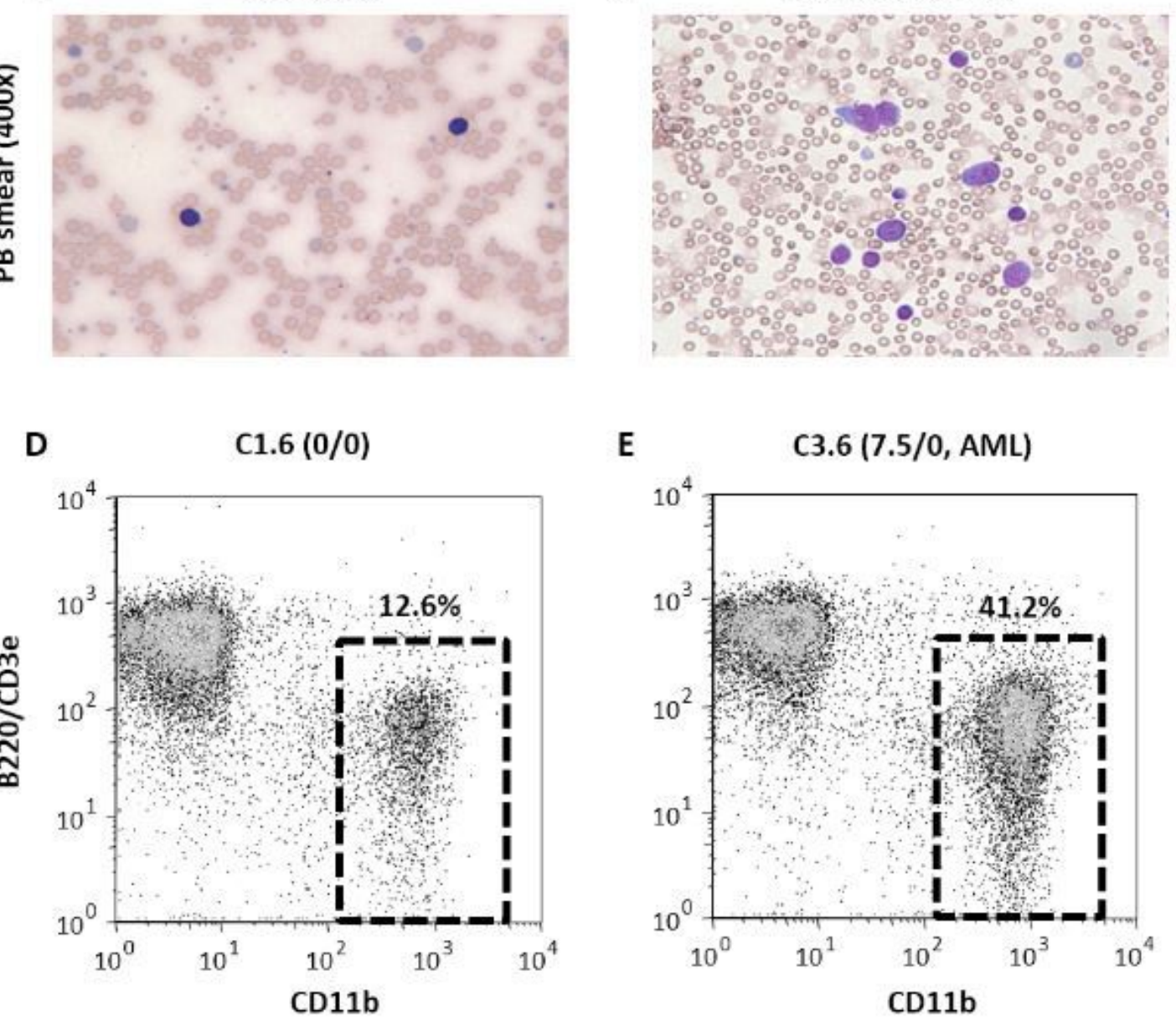

Figure 1 
Manifestation of AML in irradiated mice. (A) Representative weight change over time for a non-leukemic mouse (C1.6) and a leukemic mouse (C3.7). Representative May-Grünwald-Giemsa staining of peripheral blood (PB) smear for mouse C1.6 (B) and C6.1 (C). Representative flow cytometry analysis of myeloid vs. lymphoid population in PB for mouse C1.6 (D) and C3.6 (E).
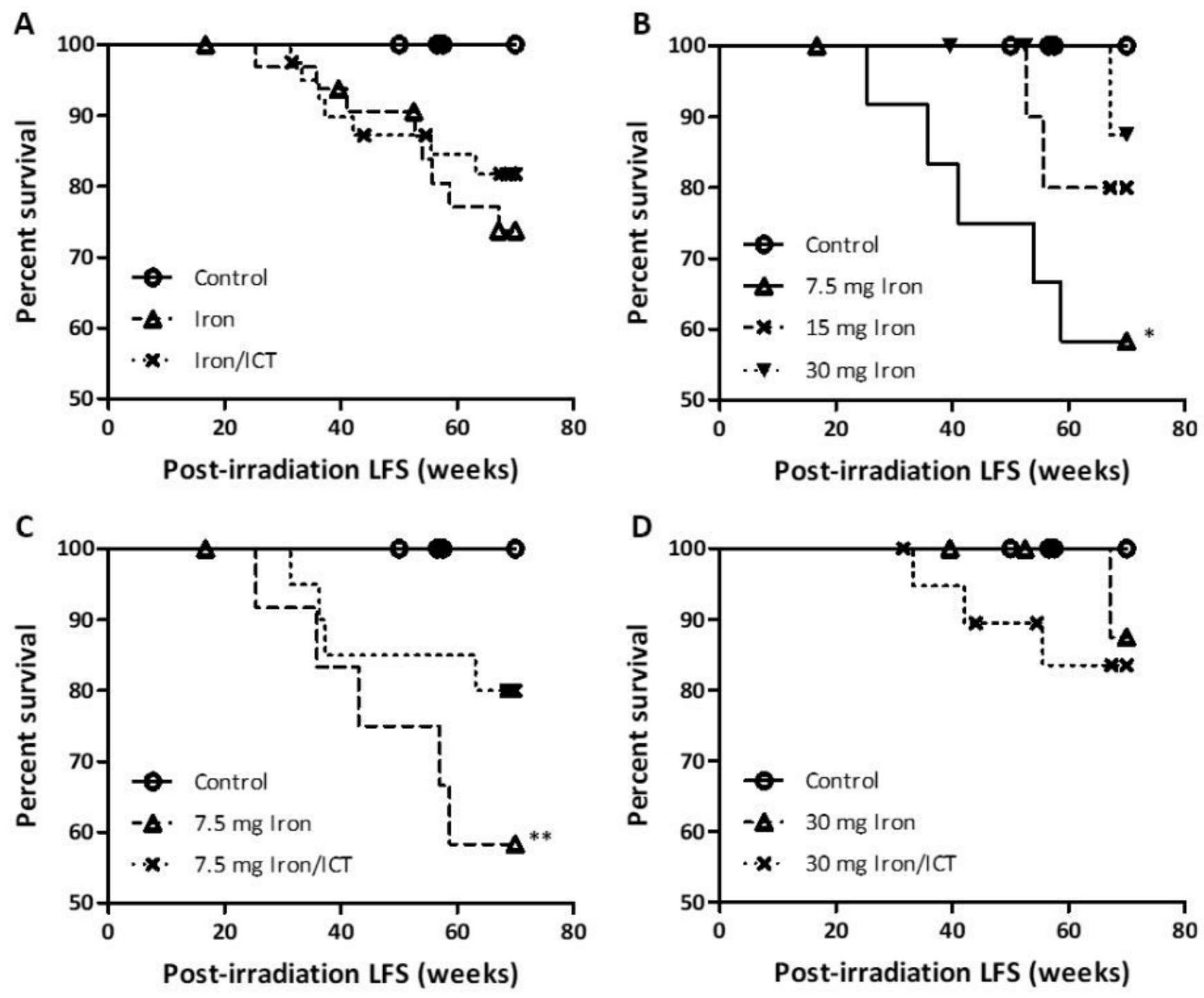

Figure 2

Kaplan-Meier (KM) leukemia-free survival (LFS) curves. (A) Control group (Iron/ICT: 0/0) versus aggregated iron injected groups $(7.5 / 0,15 / 0,30 / 0)$ and aggregated iron/deferasirox treatment groups (7.5/10, 7.5/40, 30/10 and 30/40). (B) Control (0/0) and iron injected groups (7.5/0, 15/0,30/0). (C) Control (0/0), iron injected (7.5/0) and iron/deferasirox groups (7.5/10, 7.5/40). (D) Control (0/0), iron injected $(30 / 0)$ and iron/deferasirox groups $(30 / 10,30 / 40)$ * $\mathrm{P}<0.05$ versus Control. ** logrank test for trend $\mathrm{P}<0.05$. 


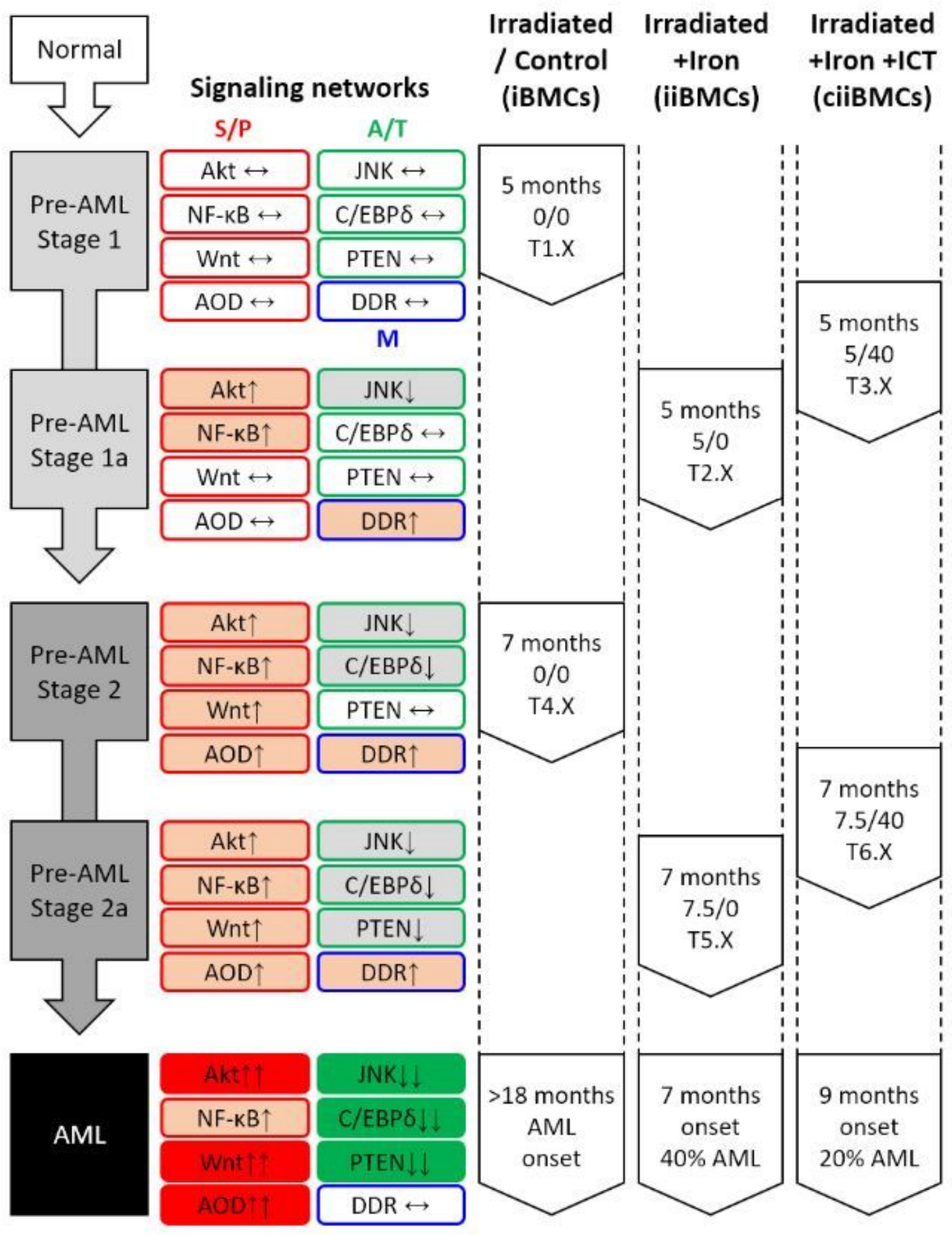

\section{Figure 3}

RI-AML progression model and the influence of iron or iron/ICT to leukemogenesis. AOD - antioxidant defenses, DDR - DNA damage response, S/P - effects on survival/proliferation, A/T - apoptosis/tumor suppression, $\mathrm{M}$ - mutagenesis. 


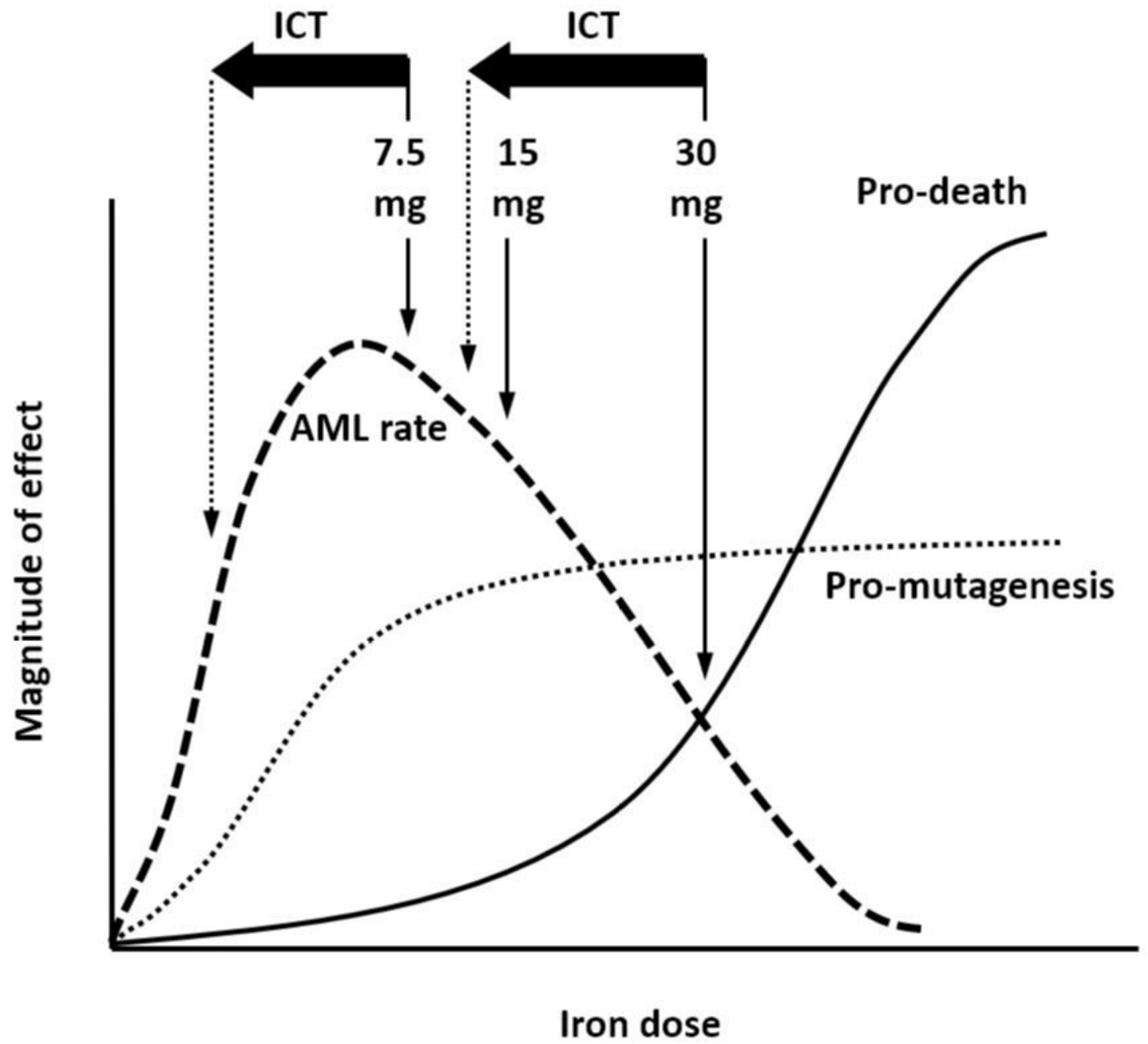

Figure 4

Proposed pro-death/mutagenic influences of iron loading and ICT on the rate of AML.

\section{Supplementary Files}

This is a list of supplementary files associated with this preprint. Click to download.

- SubmittedARRIVEChecklistBCAN200912.pdf

- SubmittedlronmussupplementaryBCAN200912.docx 